\title{
Producing Bulk Ultrafine-Grained Materials by Severe Plastic Deformation
}

\author{
Ruslan Z. Valiev, Yuri Estrin, Zenji Horita, Terence G. Langdon, Michael J. Zehetbauer, \\ and Yuntian T. Zhu
}

This overview highlights very recent achievements and new trends in one of the most active and developing fields in modern materials science: the production of bulk ultrafine-grained (UFG) materials using severe plastic deformation (SPD). The article also summarizes the chronology of early work in SPD processing and presents clear and definitive descriptions of the terminologycurrently in use in this research area. Special attention is given to the principles of the various SPD processing techniques as well as the major structural features and unique properties of bulk UFG materials that underlie their prospects for widespread practical utilization.

\section{INTRODUCTION}

Interest in the processing of bulk ultrafine-grained materials through the application of severe plastic deformation has grown significantly over the last decade. ${ }^{1-3}$ However, this research has developed so rapidly in recent years that the meanings of the terminology within this subsection of materials science have remained poorly defined. It is appropriate, therefore, to take this opportunity to first formally define two terms widely used within the field: ultrafine-grained (UFG) materials and severe plastic deformation (SPD).

With reference to the characteristics of polycrystalline materials, UFG materials may be defined as polycrystals having very small grains with average grain sizes less than $\sim 1 \mu \mathrm{m}$. Thus, the grain sizes of UFG materials lie within the submicrometer $(100-1,000 \mathrm{~nm})$ and nanometer (less than $100 \mathrm{~nm}$ ) ranges. For bulk UFG materials, there are additional requirements of fairly homogeneous and reasonably equiaxed microstructures, with a majority of the grain boundaries having high angles of misorientation.
In practice, the presence of a large fraction of high-angle grain boundaries is important in order to achieve advanced and unique properties. ${ }^{4}$

Processing by SPD refers to various experimental procedures of metal forming that may be used to impose very high strains on materials leading to exceptional grain refinement. A unique feature of SPD processing is that the high strain is imposed without any significant change in the overall dimensions of the workpiece. Another feature is that the shape is retained by using special tool geometries that prevent free flow of the material and thereby produce a significant hydrostatic pressure. The presence of this hydrostatic pressure is essential for achieving high strains and introducing the high densities of lattice defects necessary for exceptional grain refinement.

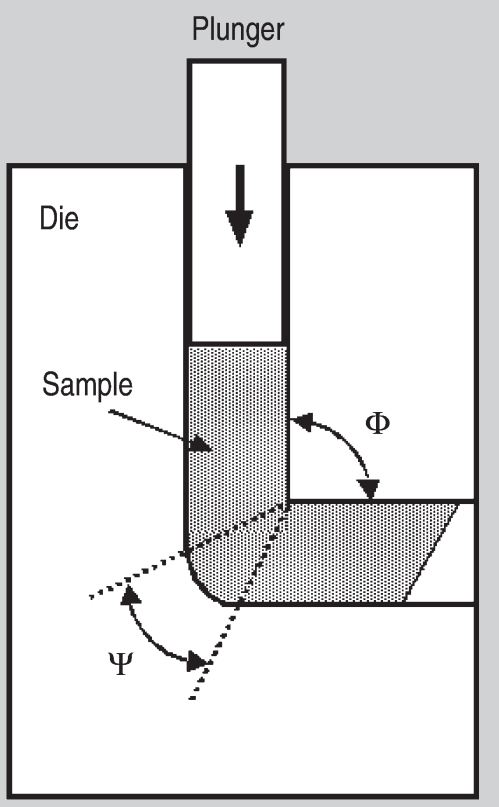

Figure 1. The principle of ECAP.
The principles of SPD processing are demonstrated in such techniques as high-pressure torsion (HPT), twist extrusion (TE), and multi-directional forging (MDF), where the initial dimensions of the samples are reasonably retained. However, SPD processing excludes more conventional forming operations such as uniaxial tension and compression, unidirectional extrusion, rolling, or drawing even if these procedures include the imposition of fairly severe strains. The application of SPD processing permits the relatively easy fabrication of bulk UFG materials having typically more than 1,000 grains in any direction within the sample volume. Ultrafine-grained materials produced in this way have submicrometer grain structures and are generally designated nanoSPD materials.

Numerous techniques for SPD processing are now available. The major methods already established for the fabrication of UFG materials are HPT, TE, MDF, equal-channel angular pressing (ECAP), accumulative roll-bonding (ARB), cyclic extrusion and compression (CEC), and repetitive corrugation and straightening (RCS). The principles of these various processes are outlined in this paper, as well as the major structural features and unique properties of bulk UFG materials, the areas of current interest, and new trends within this research field. See the sidebar on page 34 for details on the terminology used in SPD processing.

\section{TECHNIQUES FOR SPD PROCESSING}

\section{Equal-Channel Angular Pressing}

Equal-channel angular pressing ${ }^{10}$ is at present the most developed SPD processing technique. As illustrated in Figure 1, a rod-shaped billet is pressed 
through a die constrained within a channel which is bent at an abrupt angle. A shear strain is introduced when the billet passes through the point of intersection of the two parts of the channel. Since the cross-sectional dimensions of the billet remain unchanged, the pressings may be repeated to attain exceptionally high strains. The equivalent strain, $\varepsilon$, introduced in ECAP is determined by a relationship incorporating the angle between the two parts of the channel, $\Phi$, and the angle representing the outer arc of curvature where the two parts of the channel intersect, $\Psi$. The relationship is given by: ${ }^{11}$

$$
\begin{aligned}
\varepsilon & =(N / \sqrt{ } 3)[2 \cot \{(\Phi / 2)+(\Psi / 2)\} \\
& +\Psi \operatorname{cosec}\{(\Phi / 2)+(\Psi / 2)\}]
\end{aligned}
$$

where $\mathrm{N}$ is the number of passes through the die.

During repetitive pressings, the shear strain is accumulated in the billet, lead- ing ultimately to a UFG structure. In practice, different slip systems may be introduced by rotating the billet about its longitudinal axis between each pass ${ }^{12}$ and this leads to four basic processing routes: there is no rotation of the billet in route $\mathrm{A}$, rotations by $90^{\circ}$ in alternate directions or the same direction in routes $\mathrm{B}_{\mathrm{A}}$ and $\mathrm{B}_{\mathrm{C}}$, respectively, and rotations by $180^{\circ}$ in route $\mathrm{C} .{ }^{13}$ When using a die with a channel angle of $\Phi=90^{\circ}$, route $B_{C}$ is generally the most expeditious way to develop a UFG structure consisting of homogeneous and equiaxed grains with grain boundaries having high angles of misorientation.

There have also been numerous recent modifications of conventional ECAP that are designed to yield more efficient grain refinement including the incorporation of a back-pressure, the development of continuous processing by ECAP, and others.

\section{HISTORICAL BACKGROUND OF THE TERMINOLOGY USED IN SPD PROCESSING}

The early publications dealing with the production of bulk ultrafine-grained (UFG) materials by severe plastic deformation (SPD) processing appeared in the western literature in the early 1990s, although there were also several contemporaneous publications appearing in Russian journals. At that early stage, the main interest was devoted primarily to examining the unusual microstructures and properties of these materials rather than the precise significance of the SPD processing. The first paper in this area ${ }^{5}$ received relatively little attention but a later report, ${ }^{6}$ which provided clear evidence for UFG structure formation by SPD, became a classic publication and is currently listed with more than 300 separate citations. This early paper attempted also to identify similarities and differences between the grain boundaries in SPD-produced UFG materials and in the conventional nanocrystalline solids fabricated by consolidation procedures such as inert gas condensation. At that time, the terminology in use was "intensive plastic deformation."

The term "severe plastic deformation" was first introduced in a short paper describing the deformation of an $\mathrm{Al}-4 \% \mathrm{Cu}-0.5 \% \mathrm{Zr}$ alloy using high-pressure torsion, ${ }^{7}$ but the term became widely recognized in the field when it was subsequently used in an overview describing the structure and properties of UFG metals processed through SPD. ${ }^{8}$ This latter paper also received very extensive attention and is now listed with more than 400 citations.

The samples produced in this way were reasonably defined as bulk samples because typically they had 1,000 or more grains in any direction. An important consideration was also the creation of a homogeneous UFG microstructure throughout the bulk sample so that the processed solids consisted of reasonably equiaxed grains separated by predominantly high-angle grain boundaries. Initially, these structures were designated "submicrometer-grained structures" since the grain sizes were typically on the order of a few hundreds of nanometers but later x-ray studies revealed domain sizes on the order of $\sim 40-50 \mathrm{~nm}$ associated with localized distortions of the crystalline lattice and substructure. This led to the introduction of the term "bulk nanostructured materials.",

The formal definitions used for these various terms are as follows:

- Processing by SPD deformation: Any method of metal forming under an extensive hydrostatic pressure that may be used to impose a very high strain on a bulk solid without the introduction of any significant change in the overall dimensions of the sample and having the ability to produce exceptional grain refinement.

- Bulk UFG materials: Bulk materials having fairly homogeneous and equiaxed microstructures with average grain sizes less than $\sim 1 \mu \mathrm{m}$ and with a majority of boundaries having large angles of misorientation.

Through the use of processing by SPD, it is possible to produce bulk nanostructured materials with internal domains, dislocation cells, or other structural features within the grains having dimensions less than $100 \mathrm{~nm}$.

\section{High-Pressure Torsion}

High-pressure torsion refers to processing in which the sample, generally in the form of a thin disk, is subjected to torsional straining under a high hydrostatic pressure: the principle of HPT is illustrated schematically in Figure 2a. ${ }^{14}$ The disk is located within a cavity, a hydrostatic pressure is applied, and plastic torsional straining is achieved by rotation of one of the anvils. In order to achieve pressures higher than $2 \mathrm{GPa}$, it is generally preferable to use a modified geometry with the cavities placed in each of the two anvils, as shown in Figure $2 \mathrm{~b} .{ }^{15,16}$ If there is no outward flow of material, the disk thickness remains constant and the true torsional strain, $\gamma$, is given by $\gamma=(\mathrm{r} / \mathrm{h}) \varphi$, where $\mathrm{r}$ is the distance from the center of the disk, $\varphi$ is the torsional angle in radians, and $h$ is the sample thickness. An alternative relationship is also available if there is some outward flow of material between the two anvils and a corresponding reduction in the value of h. ${ }^{14}$ For comparison with other SPD methods, the true equivalent strain, $\varepsilon$, can be calculated using the relation $\varepsilon=$ (1/a) $\gamma$, where the coefficient a takes either the values from a plastic flow criterion (where $\mathrm{a}=2$ for Tresca and $\mathrm{a}=\sqrt{ } 3$ for von Mises) or from the Taylor theory for polycrystals (where $\mathrm{a}=1.65$ for texturefree face-centered cubic [fcc] metals and decreases slightly to lower values during continued deformation). The relatively small disks used in conventional HPT are attractive for products such as small bulk nanomagnets with enhanced soft and hard magnetic properties, arterial stents, and devices for microelectromechanical system applications. There have also been recent attempts to extend HPT to include the processing of larger bulk samples. ${ }^{17}$

\section{Accumulative Roll-Bonding}

The technique of accumulative rollbonding makes use of a conventional rolling facility. As illustrated in Figure $3,{ }^{18}$ a sheet is rolled so that the thickness is reduced to one-half of the thickness in a pre-rolled condition. The rolled sheet is then cut into two halves that are stacked together. To achieve good bonding during the rolling operation, the two contact faces are degreased and wire-brushed before placing them in contact and the 


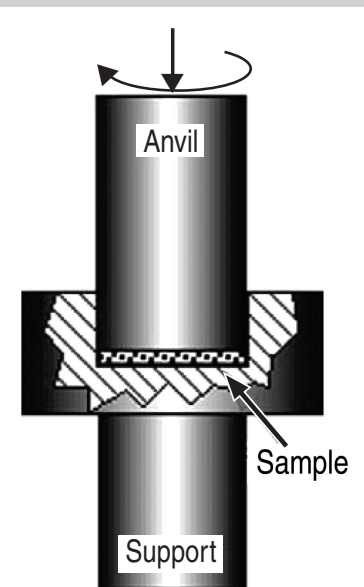

a

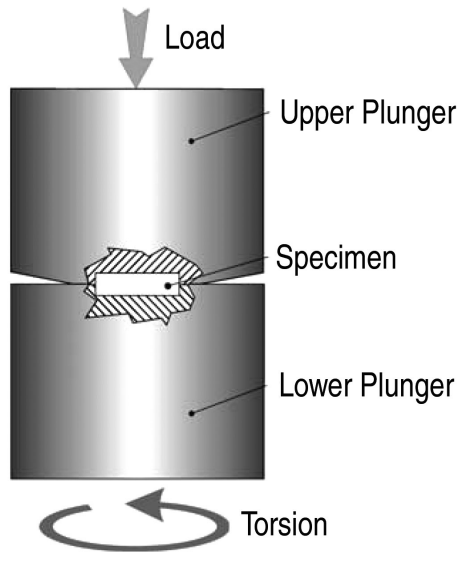

Figure 2. The principle of HPT: (a) tool with a sample located within a cavity in the support anvil and (b) tool with cavities in both anvils. stacked sheets are then rolled again to one-half thickness. Thus, a series of rolling, cutting, brushing, and stacking operations are repeated so that ultimately a large strain is accumulated in the sheet. It is possible to heat the sheet when rolling but at a temperature where there is no recrystallization. For the ARB process, the equivalent strain after $\mathrm{N}$ cycles, $\varepsilon_{\mathrm{N}}$, is given by $\varepsilon_{\mathrm{N}}=0.80 \mathrm{~N} .{ }^{18}$

In practice, the UFG structure produced by ARB is not three-dimensionally equiaxed but rather there is a pancakelike structure which is elongated in the lateral direction. This microstructural feature is the same irrespective of the types of metals and alloys. The ARB process may be applied for the production of metal-matrix composites by sheathing mixed powders and subjecting them to a roll-bonding process. ${ }^{19}$

\section{Multi-Directional Forging}

Multi-directional forging was applied for the first time in the first half of the 1990s for the formation of UFG structures in bulk billets. ${ }^{20,21}$ The process of MDF is usually associated with dynamic recrystallization in single-phase metals/ alloys.

The principle of MDF is illustrated in Figure 4 and it assumes multiple repeats of free-forging operations including setting and pulling with changes of the axes of the applied load. The homogeneity of the strain produced by MDF is lower than in ECAP and HPT. However, the method can be used to obtain a nanostructured state in rather brittle materials because processing starts at elevated temperatures and the specific loads on tooling are relatively low. The choice of the appropriate temperature-strain rate regimes of deformation leads to the desired grain refinement. The operation is usually realized over the temperature interval of $0.1-0.5 \mathrm{~T}_{\mathrm{m}}$, where $\mathrm{T}_{\mathrm{m}}$ is the absolute melting temperature, and it is useful for producing large-sized billets with nanocrystalline structures. ${ }^{22}$

\section{Cyclic Extrusion and Compression}

Cyclic extrusion and compression (also sometimes called "hourglass pressing") is performed by pushing a sample from one cylindrical chamber of diameter $d_{0}$ to another with equal dimensions through a die with diameter $\mathrm{d}_{\mathrm{m}}$ which is markedly smaller than $\mathrm{d}_{0}, 23$ the principle is illustrated in Figure 5. Thus, the processing induces extrusion and the chambers provide compression so that, during one cycle, the material is pushed to first experience compression, then extrusion, and finally compression again. The true strain produced in one cycle is calculated as $\Delta \varepsilon=4 \ln \left(\mathrm{d}_{\mathrm{o}} / \mathrm{d}_{\mathrm{m}}\right)$. In the second cycle, the extrusion direction is reversed, leading to the same sequence of deformation modes. The process can be repeated $\mathrm{N}$ times by pushing the sample back and forth to give an accumulated true strain of $(\mathrm{N} \Delta \varepsilon)$. With a diameter ratio of typically $\mathrm{d}_{\mathrm{m}} / \mathrm{d}_{\mathrm{o}} \approx 0.9$, the strain imposed on the material in one cycle is $\Delta \varepsilon \approx 0.4$. Accumulated true strains of up to 90 have been reported ${ }^{23}$ with sample dimensions of about $25 \mathrm{~mm}$ in length and $10 \mathrm{~mm}$ in diameter. The deformation speed is as low as $\sim 0.2 \mathrm{~mm} / \mathrm{s}$ in order to limit heating of the specimen to $<5$ K. Although the strains reached with this method are much higher than those with any unidirectional SPD technique, the microstructure and/or mechanical properties are similar because of the extra annihilation of dislocations due to the cyclic character of the straining. ${ }^{24}$

\section{Repetitive Corrugation and Straightening}

Repetitive corrugation and straightening was introduced recently and the principle is illustrated in Figure $6 .{ }^{25}$ In a repetitive two-step process, the workpiece is initially deformed to a corrugated shape and then straightened between two flat platens using a processing cycle that may be repeated many times. The RCS facility illustrated in Figure 6 subjects the workpiece to both bending and shear, which promotes grain refinement.

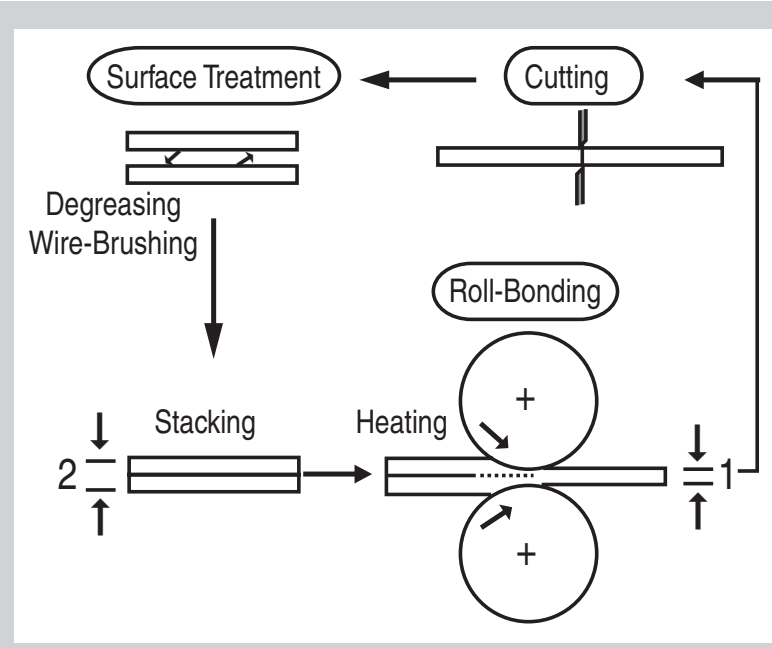

Figure 3. The principle of ARB. ${ }^{18}$ 
Processing by RCS was used to produce nanostructures in a copper sample with an average initial grain size of $760 \mu \mathrm{m} .{ }^{25,26}$ A similar procedure was used later for grain refinement of aluminum. ${ }^{27}$

An advantage of RCS is that it can be adapted easily to current industrial rolling facilities. It is not difficult to machine a series of corrugating teeth into the rollers of a conventional rolling mill, thus enabling the RCS process, and this has the potential of producing nanostructured materials in a continuous and economical way. ${ }^{28}$ The RCS technique is currently in the early stages and further research is needed to develop the process to a mature SPD technique for producing nanostructured materials. One critical issue is the need to design equipment and processing schedules for improving microstructural homogeneity.

\section{Twist Extrusion}

The use of TE for grain refinement was introduced in $2004^{29}$ and the principles are illustrated in Figure 7. During TE, a workpiece is pushed through an extrusion die whose cross section maintains its shape and size while it is twisted through a designated angle around its longitudinal axis. As a result, the workpiece regains its shape and size after each TE pass and thus it is possible to repetitively process a sample for excellent grain refinement. A variety of cross-sectional shapes, but not circular geometries, are possible with this technique. In practice, and by analogy to HPT, the plastic strain is not uniform across the cross section but the plastic strain increases with the distance from the axis so that the more distant regions have a finer grain size. This microstructural heterogeneity leads to inhomogeneous mechanical properties with the cross-sectional center having the lowest strength. It is anticipated that the microstructural homogeneity may improve with increasing numbers of TE passes.

See the sidebar on page 37 for background on the development of nanoSPD in materials science.

\section{BULK UFG MATERIALS: MAIN STRUCTURAL FEATURES AND PROPERTIES}

The average grain size achieved in pure metals using various SPD techniques usually lies in the range of $\sim 150-300$ $\mathrm{nm}$ but in alloys it may be significantly smaller. ${ }^{9}$ For example, using HPT with the intermetallic $\mathrm{Ni}_{3} \mathrm{Al}$ produced a grain size of $60 \mathrm{~nm}$ and in TiNi alloys processing by HPT led to total amorphization. . $^{32,33}$ At the same time, the structural features of SPD-processed metals are quite complex and they are characterized not only by the formation of ultrafine grains but also by the presence of non-equilibrium

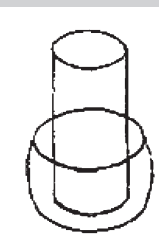

a
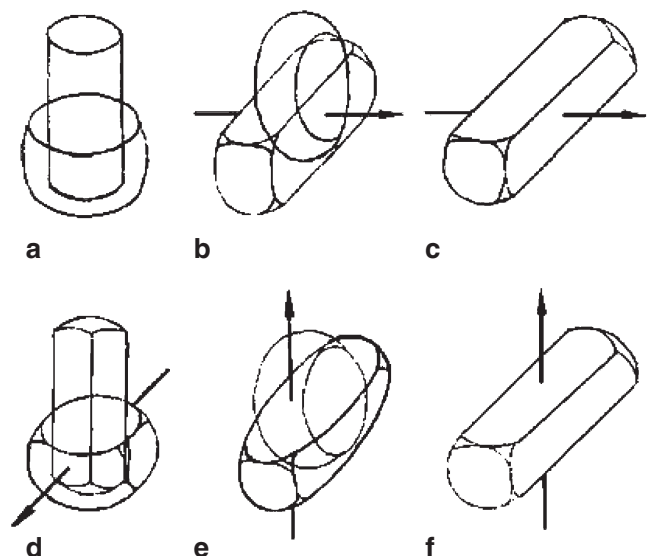

c

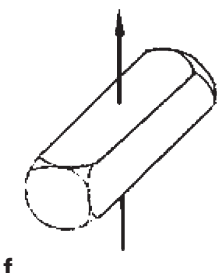

f

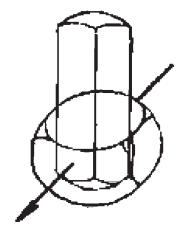

g

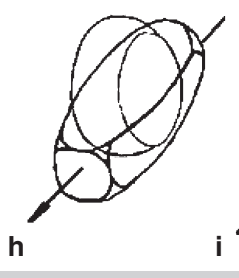

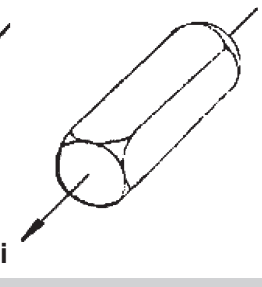

Figure 4. The principle of MDF (a), (b), and (c) show setting and pulling along the first axis, (d), (e), and (f) show setting and pulling along the second axis, and (g), (h), and (i) show setting and pulling along the third axis. ${ }^{20}$

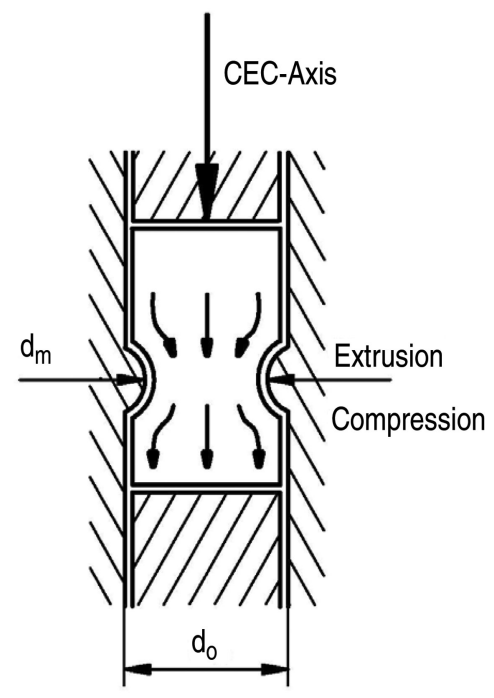

Figure 5. The principle of CEC.

grain boundaries with a high density of extrinsic (as opposed to geometrically necessary) dislocations and vacancies, ${ }^{26,34}$ high lattice distortions, and possibly, changes in the local phase composition..$^{9,35}$

The genesis of UFG structures produced by SPD techniques is not yet fully understood. While some authors relate them to in-situ recrystallization, ${ }^{36}$ others place the origin in the formation or fragmentation of a dislocation cell structure whose size scale decreases as the stress rises during SPD processing. ${ }^{37-39}$ The accumulation of the misorientation between neighboring dislocation cells occurs in parallel with the decrease of the average cell size and leads to a gradual transformation of the dislocation cell structure. In particular, predominantly polarized dipole walls yield a new refined grain structure in which polarized tilt walls are prevalent, causing high angles of misorientation between the grains. ${ }^{38,39}$ According to this view, the smallest grain size achievable by SPD cannot be smaller than the length scale of the precursor structure and thus of the dislocation cell size, which has an order of magnitude of some hundreds of nanometers. Recently, it was found that HPT processing of electrodeposited nickel induced the growth of grains to a final size close to the lower grain size limit for HPT refinement of coarse-grained nickel, suggesting that there exists a final grain size determined by the processing parameters rather than 


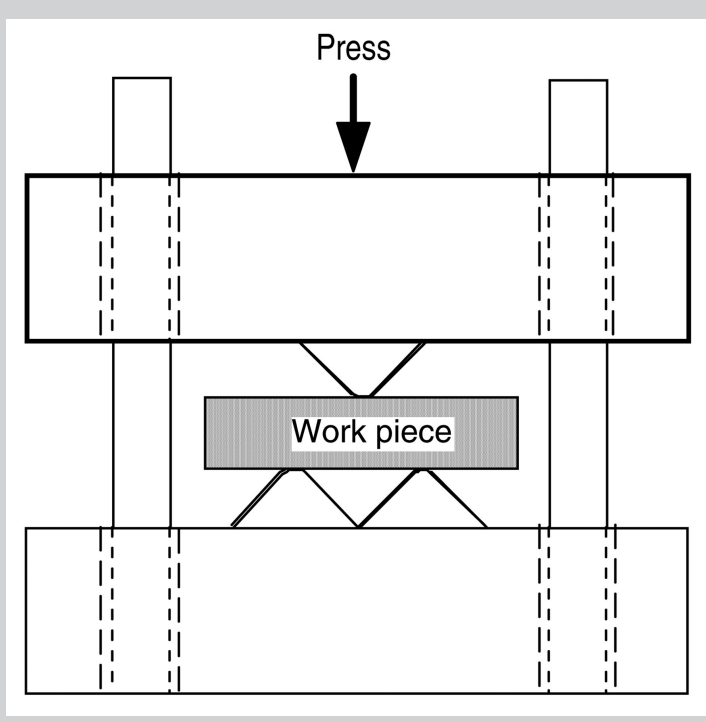

Figure 6. The principle of RCS..$^{25,26}$

by the total imposed strain. ${ }^{40}$ Nevertheless, a consistent model explaining the formation of nanosized grains by SPD processing is yet to be developed.

The most important feature of SPD processing is that it leads to exceptional grain refinement and thereby provides an opportunity to significantly enhance the properties of materials as well as to attain novel and/or unique properties. One such unique property is the unexpected combination of high strength and high ductility which was observed for the first time in UFG copper and titanium ${ }^{41}$ and later demonstrated for a range of metals and alloys processed by SPD. ${ }^{4,42-44}$ At the same time, these studies revealed that the unique combination of high strength and high ductility is conditioned by subtle structural features of UFG materials such as the non-equilibrium state of the grain boundaries, the availability of a bimodal grain distribution, or the presence of nanoparticles of second phases. These results lead to the emergence of new deformation mechanisms in nanostructured solids including the occurrence of grain boundary sliding at low temperatures ${ }^{45}$ and the generation of partial dislocations and twinning. ${ }^{46}$ The specific processing of SPD and the associated simultaneous improvement of both strength and ductility is probably responsible also for the marked enhancement of fatigue strength and fracture toughness in these materials. ${ }^{47}$ Another extraordinary property of UFG materials is their ability to exhibit superplastic ductility at exceptionally high strain rates and unusually low temperatures, $, 9,48$ which provides an opportunity for the rapid superplastic forming of complexshaped parts for use in the transportation and consumer product industries. ${ }^{49}$ properties. ${ }^{6,8}$
Although most efforts to date have been directed toward improving the mechanical properties of structural materials processed by SPD, there is also recent evidence for other interesting developments. A general observation is that the increase in grain boundary area introduced by SPD can lead to enhancements in various kinetic properties of metallic materials. For example, it was found that the kinetics of plasma nitriding of several steels is accelerated by pretreatment by HPT. ${ }^{50}$ Similarly, but more importantly in view of potential applications with environmental considerations, it was shown that the kinetics of hydrogen absorption/desorption in magnesium alloy ZK60 are accelerated by ECAP processing and by a combination of ECAP and high-energy ball milling. ${ }^{51}$ These findings suggest interesting new avenues for SPD applications targeting the development of new functional

\section{THE DEVELOPMENT OF NanOSPD AS AN IMPORTANT AREA OF MATERIALS SCIENCE}

In principle at least, severe plastic deformation (SPD) processing has a long history, dating back to the metalworking of ancient China. ${ }^{30}$ In modern terms, the first significant evaluation of the principles of SPD processing lies in the classic early experiments by Bridgman in the United States ${ }^{31}$ where, as in modern processing, high hydrostatic pressures were effectively combined with concurrent straining. For current practitioners of SPD processing, the most important early contribution is the work of Segal and coworkers in Minsk ${ }^{10}$ where the technique of equal-channel angular pressing (ECAP) was first introduced in a form that is essentially identical to the procedure now used in many laboratories around the world. The interest in SPD processing was subsequently stimulated by the recognition that it may be used to produce exceptional grain refinement in bulk solids and thus it is a processing tool for achieving unusual and beneficial

As a consequence of this early work, there was a general recognition in the 1990s that SPD processing was becoming an important research area having a significant potential for use in a wide range of industrial applications. Accordingly, this led to the organizing of the NATO Advanced Research Workshop on Investigations and Applications of Severe Plastic Deformation, held in Moscow, Russia, in August 1999. ${ }^{1}$ Subsequently, a second meeting titled Nanomaterials by Severe Plastic Deformation was held in Vienna, Austria, in December 2002. ${ }^{2}$ At that time, an International NanoSPD Steering Committee was established to regulate these meetings and to provide assistance for associated activities within the broad field of SPD. This committee was formed with Ruslan Z. Valiev, a professor at Ufa State Aviation Technical University, as the chairman and with five additional members who constitute the co-authors of this paper. Shortly after its foundation, the committee established a website to bring together all interested participants in the SPD field and to provide broad information on new developments, publications in the field, forthcoming meetings, and a general listing of key personnel. This website can be accessed at www.nanospd.org.

Recently, the third conference in the series, designated NanoSPD3, was held in Fukuoka, Japan, in September 2005. ${ }^{3}$ This conference aimed not only to evaluate new properties through SPD processing but also to bring new ideas for its practical applications. The next international conference in the series, NanoSPD4, will be held on 17-22 August, 2008, in Goslar, Germany, under the chairmanship of Yuri Estrin, a professor at Clausthal University of Technology. Full details of this meeting are available on the official website: www.iww.tu-clausthal.de/NanoSPD4. 


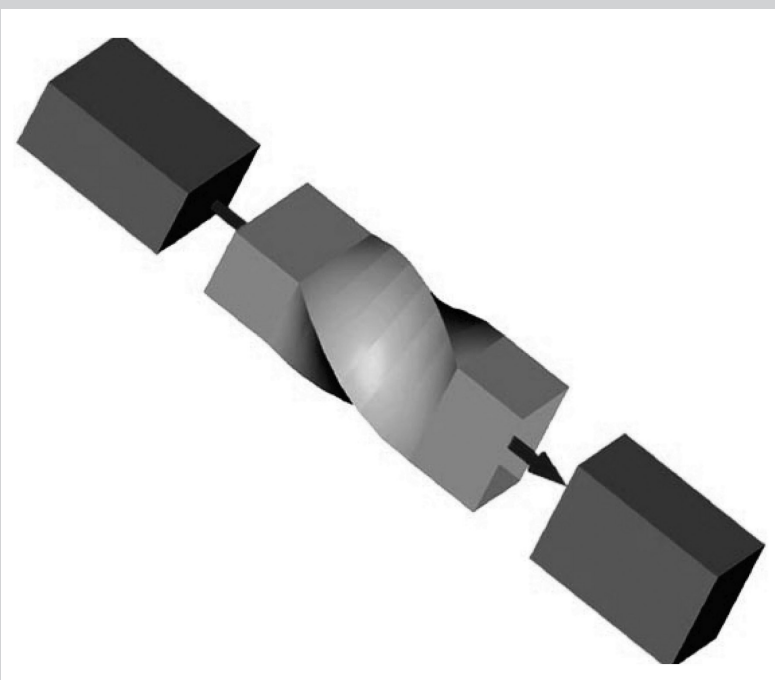

Figure 7. The principle of TE. ${ }^{29}$ The illustration shows the shapes of a workpiece before entering a TE die, inside the die, and after exiting the die where the workpiece is deformed by twisting within the TE die. materials.

It should be emphasized that the complex structure of SPD-processed materials may also result in multifunctional properties. For example, the nanostructured TiNi alloy demonstrates an extraordinary combination of very high mechanical and functional properties including superelasticity and a shapememory effect. ${ }^{52}$ Such a combination in the TiNi alloy is in stark contrast to its conventional coarse-grained counterpart. Another example is SPD-processed magnetic materials such as Fe-Co. ${ }^{53}$ Not only does the nanometer grain size induce advanced mechanical properties but it leads also to enhanced soft magnetic properties due to an interaction of magnetic moments across the grain boundaries in these materials. Thus, the engineering of multifunctional materials is rapidly becoming a new direction in the science of SPD nanomaterials.

\section{ONGOING RESEARCH AND TRENDS}

Markets for bulk nanostructured materials appear to exist in every product sector where superior mechanical properties (in particular, high strength, good strength-to-weight ratio, and excellent fatigue life) are critical. Formal market analyses have identified a wide range of potential applications for nanometals in various industries including aerospace, transportation, medical devices, sports products, food and chemical processing, electronics, and conventional defense. ${ }^{54}$ Therefore, it is reasonable to anticipate that nanostructuring aimed at an enhancement of the properties of materials will remain the basic task of SPD processing into at least the near future. New opportunities are provided by recent findings in the nanoSPD area such as SPD-induced phase transformations ${ }^{55-57}$ and SPD-induced vacancy generation, ${ }^{58}$ both of which may lead to the formation of novel nanostructures and properties.

At the present, the SPD techniques are starting to emerge from laboratoryscale research and to gain increasing appreciation and understanding for the potential commercial applications of various UFG materials. ${ }^{54,59-62}$ This evolution is revealed in several ways. First, both pure metals and commercial alloys are currently under extensive research and the latter have a great potential for special applications. Second, growing attention is being directed within the SPD community to the development of economically feasible continuous production methods for the processing of UFG metals and alloys. ${ }^{61-63}$ As an example, two different processing routes, including ECAP, were used recently for the systematic fabrication of long rods from nanostructured titanium materials for medical applications. ${ }^{61}$ Specifically, using a combination of ECAP and thermomechanical treatments with a commercial-purity titanium, it was possible to achieve a yield stress of 1,100 $\mathrm{MPa}$ and ultimate tensile strength of 1,230 MPa together with a reasonable elongation to failure of $\sim 14 \% .{ }^{64}$ Using this procedure, titanium rods were fabricated with diameters of $6.5 \mathrm{~mm}$ and lengths of more than $800 \mathrm{~mm}$ and with varia- tions in the mechanical properties along their lengths of not more than $\pm 5 \%$. An important additional consideration was that the rate of material utilization was more than $65 \%$. These results provide a clear demonstration of the great potential inherent in using a combination of SPD processing and thermomechanical treatments for the commercial production of semi-products from titanium for medical applications. It is anticipated that similar approaches may be used also to fabricate UFG materials for a range of other applications as, for example, in weight-sensitive products such as high-performance mountain bicycles and automotive components. ${ }^{59}$

Scaling to larger billet sizes is equally feasible in SPD processing. A recent investigation evaluated the effect of upscaling on the mechanical properties, microstructure, and hot-workability of an Al-6061 alloy from a laboratory scale with a diameter of $12.5 \mathrm{~mm}$ to an industrial scale with a diameter of $100 \mathrm{~mm}{ }^{65}$ This latter investigation and all earlier studies have consistently confirmed the feasibility of up-scaling ECAP processing for the fabrication of large-scale components. Alternatively, down-scaling of the SPD processing techniques may open up interesting new directions in the fabrication of micro-mechanical devices. A recent report described the first results of ECAP processing using millimeter-scale dies ${ }^{66}$ and another SPDlike process, so-called solid-state infiltration, was also proposed where there was a penetration of solid aluminum in a porous steel preform under a high imposed pressure. ${ }^{67}$ Although these techniques are in their infancy, the general philosophy and the basic features of SPD processing are clearly also applicable in this domain.

\section{ACKNOWLEDGEMENTS}

Preparation of this paper was supported by the International Science and Technology Center (Moscow) under the New Independent States-Industrial Partnering Program project LANL-T2-0199 and the Russian Federation for Basic Research (RZV), by the DFG under project ES 74/12-1 (YE), by a grantin-aid for scientific research from the Ministry of Education, Science, Sports and Culture of Japan (ZH), by the U.S. Army Research Office under Grant No. W911NF-05-1-0046 (TGL), by the 
Austrian Science Foundation under grant No. 17095 N02 (MJZ), and by the U.S. Department of Energy Initiative on Proliferation Prevention Program office (YTZ).

\section{References}

1. T.C. Lowe and R.Z. Valiev, eds., Investigations and Applications of Severe Plastic Deformation (Dordrecht, the Netherlands: Kluwer, 2000).

2. M.J.Zehetbauer and R.Z.Valiev, eds., Nanomaterials by Severe Plastic Deformation (Weinheim, Germany: Wiley-VCH, 2004).

3. Z. Horita, ed., Nanomaterials by Severe Plastic Deformation (Uetikon-Zürich, Switzerland: Trans Tech Publications, 2005).

4. R.Z. Valiev, Nature Mater., 3 (2004), p. 511.

5. R.Z. Valiev, R.R. Mulyukov, and V.V. Ovchinnikov, Phil. Mag. Lett., 62 (1990), p. 253

6. R.Z. Valiev, N.A. Krasilnikov, and N.K. Tsenev, Mater. Sci. Eng., A137 (1991), p. 35.

7. R.S. Musalimov and R.Z. Valiev, Scripta Metall. Mater., 27 (1992), p. 1685.

8. R.Z. Valiev, A.V. Korznikov, and R.R. Mulyukov, Mater. Sci. Eng., A168 (1993), p. 141.

9. R.Z. Valiev, R.K. Islamgaliev, and I.V. Alexandrov, Prog. Mater. Sci., 45 (2000), p. 103.

10. V.M. Segal et al., Russian Metall., 1 (1981), p. 99. 11. Y. Iwahashi et al., Scripta Mater., 35 (1996), p. 143.

12. V.M. Segal, Mater. Sci. Eng., A197 (1995), p. 157.

13. M. Furukawa et al., Mater. Sci. Eng., A257 (1998), p. 328.

14. A.P. Zhilyaev et al., Acta Mater., 51 (2003), p. 753.

15. A. Vorhauer and R. Pippan, Scripta Mater., 51 (2004), p. 921.

16. T. Hebesberger et al., Acta Mater., 53 (2005), p. 393.

17. G. Sakai et al., Mater. Sci. Eng., A406 (2005), p. 268.

18. Y. Saito et al., Acta Mater., 47 (1999), p. 579.

19. S.H. Lee et al., Mater. Trans. JIM, 40 (1999), p. 1422.

20. O.R. Valiakhmetov, R.M. Galeyev, and G.A. Salishchev, Fiz. Metall. Metalloved, 10 (1990), p. 204.

21. R.M. Galeyev, O.R. Valiakhmetov, and G.A. Salishchev, Russian Metall., 4 (1990), p. 97.

22. S.V. Zherebtsov et al., Scripta Mater., 51 (2004), p. 1147.

23. J. Richert and M. Richert, Aluminium, 62 (1986), p. 604.

24. M. Richert et al., Mater. Sci. Eng., A355 (2003), p. 180.

25. Y.T. Zhu et al., Metall. Mater. Trans., 32A (2001), p. 1559.

26. J. Huang et al., Acta Mater., 49 (2001), p. 1497

27. D.H. Shin et al., Mater. Sci. Eng., A298 (2002), p. 98.

28. J.Y. Huang et al., Mater. Sci. Eng., A371 (2004), p. 35.

29. D.V. Orlov et al., Ultrafine Grained Materials III, ed. Y.T. Zhu et al. (Warrendale, PA: TMS, 2004), p. 457

30. J.T. Wang, Mater. Sci. Forum, 503-504 (2006), p. 363.

31. P.W. Bridgman, Studies in Large Plastic Flow and Fracture (New York: McGraw-Hill, 1952).

32. A.V. Sergueeva et al., Mater. Sci. Eng., A339 (2003), p. 159.

33. X.Z. Liao et al., Appl. Phys. Lett., 84 (2004), p. 592

34. E. Schafler et al., Mater. Sci. Eng., A410-411 (2005), p. 169

35. S.V. Dobatkin, V.V. Zakharov, and L.L. Rokhlin, Mater. Sci. Forum, 503-504 (2006), p. 399.

36. R. Lapovok et al., J. Mater. Sci., 40 (2005), p. 1.

37. Y. Estrin et al., Mater. Sci. Forum, 503-504 (2006), p. 675.

38. T. Ungár and M. Zehetbauer, Scripta Mater., 35 (1996), p. 1467.

39. M. Zehetbauer et al., Acta Mater., 47 (1999), p. 1053.

40. X.Z. Liao et al., Appl. Phys. Lett., 88 (2006), p. 021909

41. R.Z. Valiev et al., J. Mater. Res., 17 (2002), p. 5.

42. Y. Wang et al., Nature, 419 (2002), p. 912.

43. Y.T. Zhu and X. Liao, Nature Mater., 3 (2004), p. 351.

44. Z. Horita et al., Adv. Mater., 17 (2005), p. 1599.

45. N.Q. Chinh et al., Adv. Mater., 18 (2006), p. 34.

46. Y.T. Zhu et al., J. Appl. Phys., 98 (2005), p. 034319.

47. H.W. Höppel et al., Intl. J. Fatigue, (2006) in press.

48. R.Z. Valiev et al., Scripta Mater., 37 (1997), p. 1945.

49. C. Xu et al., J. Mater. Eng. Perform., 13 (2004), p. 683.

50. H. Ferkel et al., Mater. Sci. Eng., A348 (2003), p. 100.

51. V. Skripnyuk et al., Acta Mater., 52 (2004), p. 405. 52. V.G. Pushin et al., Ultrafine Grained Materials III, ed. Y.T. Zhu et al. (Warrendale, PA: TMS, 2004), p. 481. 53. A. Vorhauer et al., Mater. Sci. Forum, 503-504 (2005), p. 299.

54. T.C. Lowe and Y.T. Zhu, Adv. Eng. Mater., 5 (2003), p. 373

55. X. Sauvage, F. Wetscher, and P. Pareige, Acta Mater., 53 (2005), p. 2127.

56. Yu. Ivanisenko et al., Acta Mater., 51 (2003), p. 5555.

57. N. Boucharat et al., Scripta Mater., 53 (2005), p. 823.

58. M. Zehetbauer et al., Mater. Sci. Forum, 503-504 (2006), p. 57.

59. Y.T. Zhu, T.C. Lowe, and T.G. Langdon, Scripta Mater., 51 (2004), p. 825

60. T.C. Lowe and Y.T. Zhu, Nanomaterials by Severe Plastic Deformation, ed. M.J. Zehetbauer and R.Z. Valiev (Weinheim, Germany: Wiley-VCH, 2004), p.
789

61. R.Z. Valiev, Mater. Sci. Forum, 503-504 (2006), p. 3.

62. T.C. Lowe, Mater. Sci. Forum, 503-504 (2006), p. 355

63. G.J. Raab et al., Mater. Sci. Eng., A382 (2004), p. 30.

64. V.V. Latysh et al., Mater. Sci. Forum, 503-504 (2006), p. 763

65. R. Srinivasan, B. Cherukuri, and P.K. Chaudhury, Mater. Sci. Forum, 503-504 (2006), p. 371.

66. Y. Estrin et al., Nanostructured Materials by HighPressure Severe Plastic Deformation, ed. Y.T. Zhu and V. Varyukin (Dordrecht, the Netherlands: Springer, 2006), p. 39

67. Y. Estrin et al., Mater. Sci. Eng., A410-411 (2005), p. 165 .

Ruslan Z. Valiev is with the Institute of Physics of Advanced Materials at Ufa State Aviation Technical University in Ufa, Russia. Yuri Estrin is with the Institute of Materials Science and Technology at Clausthal University of Technology in Clausthal-Zellerfeld, Germany. Zenji Horita is with the Department of Materials Science and Engineering, Faculty of Engineering at Kyushu University in Fukuoka Japan. Terence G. Langdon is with the Departments of Aerospace \& Mechanical Engineering and Materials Science at the University of Southern California in Los Angeles, California. Michael J. Zehetbauer is with the Department of Materials Physics at the University of Vienna in Wien, Austria. Yuntian T. Zhu is with the Materials Science \& Technology Division at Los Alamos National Laboratory in Los Alamos, New Mexico.

For more information, contact Terence G. Langdon, University of Southern California, Departments of Aerospace \& Mechanical Engineering and Materials Science, Los Angeles, CA 90089-1453, USA; e-mail langdon@usc.edu.

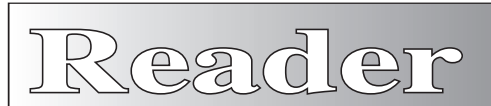

\section{TO SUBSCRIBE}

\section{PRINT OR ELECTRONIC:}

- Telephone: 1-800-759-4867 within the U.S. (724) $776-9000$ ext. 270

- E-mail: publications@tms.org

- On the web: doc.tms.org

\section{TO REPORT A PROBLEM \\ WITH YOUR \\ SUBSCRIPTION:}

- Telephone: (724) 776-9000 ext. 251

- E-mail: mcirelli@tms.org

\section{TO OBTAIN BACK}

ISSUES:

- Telephone: (724) 776-9000 ext. 251

- Fax: (724) $776-3770$

- E-mail: mcirelli@tms.org

\section{TO CHANGE YOUR}

\section{ADDRESS:}

- Telephone: (724) 776-9000 ext. 24

- On the web: members.tms.org

TMS MEMBERS:

Access JOM on-line

at no charge by visiting members.tms.org

\section{Services}

\section{TO SUBMIT AN ARTICLE:}

Check the listing of upcoming editorial

topics at www.tms.org/pubs/journals/JOM/techcalendar.htmI

Develop a 300-word abstract, including probable title and brief biographical sketch

Submit the abstract via the web at www.tms.org/pubs/journals/ JOM/abstract-author.htm/ or by fax at (724) 776-3770

TO OBTAIN REPRINTS:

Reprints are available for a fee one month after the issue is released

For information contact Mark Cirelli by e-mail at

mcirelli@ tms.org or by telephone at (724) 776-9000 ext. 251

TO OBTANN PERMISSION TO

REPRINT AN ARTICLE

Contact Trudi Dunlap by e-mail at tdunlap@tms.org or by telephone at (724) 776-9000 ext. 275

TO AGQUIRE AN INDIVIDUAL PAPER IN PORTABLE DOCUMENT FORMAT:

- Visit the document center at doc.tms.org 